ISSN: 2238-8052

\title{
A IMAGEM DO MST PRODUZIDA PELA MÍDIA E SUA INFLUÊNCIA SOBRE A FORMAÇÃO DISCURSIVA DOS DISCENTES DE UMA UNIVERSIDADE FEDERAL
}

\author{
THE IMAGE OF THE MST PRODUCED BY THE MEDIA AND ITS INFLUENCE ON THE DISCURSIVE \\ FORMATION OF THE STUDENTS OF A FEDERAL UNIVERSITY
}

\author{
Yuri Gomes FIGUEIRED0 ${ }^{1}$ \\ Daniel CALBINO²
}

Artigo recebido em 19/01/2018 e aceito em 03/12/2018

Palavras-chave:

MST;

Mídia;

Discurso

hegemônico;

Agronomia.

Key-words:

MST;

Media;

Hegemonic speech; Agronomy.

\section{R E S U M O}

O presente trabalho teve por objetivo analisar a influência da mídia sobre a percepção do MST nos estudantes de um curso de engenharia Agronômica. 0 estudo decorreu de uma pesquisa estatística-descritiva, por meio da aplicação de questionários quantitativos. Para a análise dos dados foi utilizado o Software estatístico SPSS (Statistical Package for the Social Sciences). Enquanto resultados, registrou-se que o discurso midiático foi reproduzido fielmente por um grupo de estudantes, materializado na visão de que o MST existe por influências subversivas, pela própria ignorância do campesinato e por serem baderneiros. Apesar da replicabilidade do discurso hegemônico, verificou-se um número maior de estudantes que não compartilham do mesmo pensamento. Para eles a falta de terra é a causa da existência do MST e acreditam que o MST resolveria seus problemas se ocorresse uma reforma agrária. Se considerarmos que a Agronomia representa um curso estratégico no desenvolvimento do país é fundamental para a democracia e justiça social a contextualização e problematização dos diversos atores e interesses políticos envolvidos na compreensão dos movimentos sociais da atualidade.

\begin{abstract}
A B S T R A C T
The present work had the objective of analyzing the influence of the media on the perception of the MST in the students of an agronomic engineering course. The study was based on a statistical-descriptive research, through the application of quantitative questionnaires. Statistical software SPSS (Statistical Package for the Social Sciences) was used to analyze the data. As a result, it was recorded the media discourse was faithfully reproduced by a group of students, materialized in the view that the MST exists by subversive influences, by the ignorance of the peasantry itself, and by being bulldozers. Despite the replicability of the hegemonic discourse, there was a greater number of students who did not share the same thought, for them the lack of land is the cause of the existence of the MST, and they believe that the MST would solve its problems through an agrarian reform. If we consider that Agronomy represents a strategic course in the country's development, it is fundamental for democracy and social justice in Brazil to contextualize and problematize the various actors and political interests involved in understanding the social movements in the today's society.
\end{abstract}

1 Discente de Agronomia da UFSJ Campus Sete Lagoas. Bolsista de Iniciação Científica contemplado pela agência FAPEMIG.. Email: yuri.gfigueiredo@hotmail.com.

2 Doutor em Administração pela UFMG. Mestre em Administração pela UFSJ. Especialista em Filosofia pela UFSJ. Graduado em Administração pela UFSJ. Docente Adjunto I da UFSJ Campus Sete Lagoas. E-mail: dcalbino@ufsj.edu.br. 


\section{INTRODUÇÃO}

Discutir a organização MST (Movimento dos Trabalhadores Rurais Sem Terra) ou reforma agrária no Brasil é tratar de um assunto polêmico que ilustra diversas visões de mundo. Apesar das lutas por espacialização dos movimentos camponeses na América Latina, grande parte da sociedade brasileira tem como referência os ideais que os meios hegemônicos de comunicação adotam em sua difusão (OLIVEIRA, 2013; ADISSI, 2010).

Nesta linha, falar do MST e de como o movimento é interpretado pela mídia, faz sentido em um país como o Brasil, o qual historicamente tem na lógica do latifúndio a base de sua organização agrária com uma das maiores concentrações fundiárias do mundo. Tal contexto de concentração de terras tem em contraponto o nascimento do MST, fruto da relação contraditória do sistema econômico vigente.

Todavia, o cenário agrário brasileiro e seu rico contexto de lutas entre o campesinato e a oligarquia latifundiária não se traduziu em uma sensibilidade maior do Estado sobre a questão da concentração de terras, mas somente em algumas singelas mudanças no que se refere à redistribuição de terras.

Os censos atuais mostram que o latifúndio não só se manteve historicamente, como está se fortalecendo. Dados do Instituto Nacional de Colonização e Reforma Agrária (INCRA) revelam que, entre 2010 a 2014, seis milhões de hectares passaram para as mãos dos grandes proprietários — quase três vezes o estado de Sergipe. Segundo o Sistema Nacional de Cadastro Rural, as grandes propriedades privadas saltaram de 238 milhões para 244 milhões de hectares (SNCR, 2015).

Neste cenário a relação da mídia e do MST é marcada por uma disputas de narrativas. Enquanto o MST ganhou força no cenário nacional, evidenciando suas demandas, a grande mídia relativiza as reais intenções do movimento. Segundo Adissi (2010) é atuando como partido político da classe dominante que se interpreta a forma de criminalização dos movimentos sociais perpetuada pela mídia.

Partindo desses pressupostos iniciais, o presente trabalho de natureza teórica empírica, tem por objetivo geral analisar: Quais os resultados no imaginário coletivo dos estudantes de um curso de engenharia agronômica de uma universidade federal de Minas Gerais, à luz da influência da mídia hegemônica?

O meio acadêmico apresenta diversos estudos de correlações entre estas duas categorias. Exemplos são autores aqui revisados (BERTOL,2003; ROMÃO; TFOUNI, 2004; VIERA, 2007; AYOUB, 2006; NUNES et al, 2005; ADISSI, 2010; OLIVEIRA, 2013; ROCHA, 2013 e BARBALHO, 2014) que discutem amplamente a relação da mídia com o MST. No entanto, enquanto justificativa para a área ainda carece na literatura de trabalhos que discutam o impacto do discurso hegemônico difundido pela 
mídia no contexto universitário, a tal ponto de interferir na percepção dos estudantes sobre o movimento.

Outra questão relevante para a área trata-se do próprio objeto de estudo, os estudantes de um curso de Agronomia. Pode-se considerar que este grupo de estudantes está em interface com uma profissão que possui relação direta com o campo, com a produção, com o excedente e com a própria propriedade da terra. Deste modo é relevante compreender a percepção destes atores e a própria influência da mídia neste grupo, enquanto uma categoria analítica que merece investigação.

\subsection{UM BREVE HISTÓRICO DO MST}

O movimento nascido no Paraná com representantes de 13 estados, se consolidou, cresceu e se expandiu. Para o MST a distribuição de terras não é o único objetivo do movimento. A reforma agrária é apenas o primeiro passo numa estratégia mais ampla que engloba políticas que permitam uma vida digna e de qualidade no campo. Além da reforma agrária, a luta do MST inclui a democratização da comunicação e profundas mudanças sociais (OLIVEIRA et al., 2011).

O MST se consolidou durante seus primeiros anos (1985-1990). Construiu sua imagem no cenário nacional e internacional, sendo que uma das suas maiores conquistas foi manter a pauta da reforma agrária nas discussões da sociedade brasileira (AYOUB, 2006). Esta conquista é fruto de luta, organização e resistência, marcada por grandes injustiças sociais no campo ao longo do tempo que produziu diversos levantes e revoltas de movimentos sociais. Canudos entre 1893 e 1897, Guerra do Contestado em 1913, foram alguns do exemplos de movimentos de luta pela terra que formaram as bases do movimento camponês da atualidade. O MST se autodenomina herdeiro destas lutas históricas que compõem o cenário agrário brasileiro (OLIVEIRA, 2013).

Historicamente, em 1984 na cidade de Cascavel-PR, no propósito de organizar um movimento de massa, surge o Primeiro Encontro Nacional dos Sem-Terra. O MST personifica a incorporação de lutas que vêm desde as ligas camponesas, bem como, a estratégia de realizar ocupações utilizadas pelo Movimento de Agricultores Sem Terra (MASTER³). Têm em sua origem, influências da Igreja católica e da Igreja Luterana como descreve José de Souza Martins no seu livro "A Sociedade vista do Abismo": "O MST nasceu na Igreja Católica e na Igreja Luterana através da Comissão Pastoral da Terra, em que as duas igrejas atuam juntos e de modo convergente na pastoral social. Portanto ele conserva muitas características desse nascimento e dessa origem" (Martins,2002, p.192).

Outra condição histórica que influencia na emergência do MST é o processo de modernização do campo, disseminado durante o governo militar. Marcado por políticas voltadas aos grandes

\footnotetext{
3 A estratégia de ocupações de terras se apresentou inicialmente no Movimento de Agricultores Sem Terra (MASTER), que surge no final de 1950, organizado por posseiros da região de Encruzilhado do Sul, no Rio Grande do Sul.
} 
proprietários, contribuíram radicalmente para concentração de terras e gerou profundas desigualdades sociais e econômicas. Segundo Fernandes (2000, p.49):

[...] O MST é fruto do processo histórico de resistência do campesinato brasileiro. É, portanto, parte e continuação da história da luta pela terra (...). Na década de 1970 os militares implantaram um modelo econômico de desenvolvimento agropecuário que visava acelerar a modernização da agricultura com base na grande propriedade, principalmente pela criação de um sistema de créditos e subsídios [...]

Assim, podemos observar características históricas no movimento que foram resgatadas e adaptadas como forma de resistência frente à manutenção da ordem vigente (VIERA, 2007). 0 MST representa o maior e mais organizado movimento social da América Latina. Hoje, o movimento se encontra distribuído em 24 estados nas cinco regiões do país, somando-se 350 mil famílias assentadas (MST, 2010). Conta ainda entre os assentamentos à formação de 100 cooperativas, 96 agroindústrias, e 1,9 mil associações (MST,2014). 0 movimento se denomina apartidário, apesar do relativo e aparente aparelhamento que se observou nos primeiros anos de governo petista, aonde poucas mudanças substanciais ocorreram (CRUZ; VARELA, 2009).

O movimento se perpetua através das ocupações de terras, prédios e espaços públicos, marchas e interdições em rodovias. O MST nasce expressando um novo paradigma em sua reprodução no espaço da luta, passando a se utilizar da mídia e dos modernos meios de locomoção, ampliando sua percepção no país, quebrando assim o isolamento regional que até então outros movimentos sofriam. E não somente se mantêm atuante perante a marginalização disseminada pela mídia tradicional, mas passa a compreender seu jogo, e a reproduzi-lo em seu benefício a exemplo da estratégia midiática do movimento zapatista no México (VIERA, 2007)4.

\subsection{UM BREVE HISTÓRICO DA GRANDE MÍDIA BRASILEIRA}

Apesar de o Brasil ter sido colonizado em 1500 pelos portugueses, apenas no século XIX com a chegada do Príncipe-Regente Dom João e de toda a corte portuguesa fugindo ante a invasão Napoleônica, o país passa por transformações no campo midiático. Segundo Vieira (2007) foram os interesses da coroa portuguesa em manter sua colônia alienada ante a exploração do seu domínio que realizaram um investimento na mídia.

Assim, em 1808 por necessidades da corte Lusitana em divulgar as decisões da coroa é criado a Impressão Regia no Rio de Janeiro, primeira gráfica no país, e em seguida a criação do primeiro

\footnotetext{
${ }^{4}$ A utilização amplamente difundida da internet permitiu aos zapatistas disseminarem informações e sua causa a todo mundo de forma praticante instantânea, e estabelecer uma rede de grupos de apoio que ajudaram a criar um movimento internacional de opinião pública que praticamente impossibilitou o governo mexicano de fazer o uso da repressão em larga escala (CASTELLS, 1999).
} 
jornal impresso e publicado no Brasil, a Gazeta do Rio de Janeiro. Neste período, equilibrava-se uma contraditória posição sobre as relações entre Portugal e Brasil que apresentavam interesses antagônicos quanto à soberania brasileira. Exemplo de o Conciliador do Reino Unido, que hora defendia o livre-comércio obtido em 1808, ora apostava o retorno do pacto colonial atando o Brasil.

A partir de 1821 novos jornais começaram a surgir, porém traziam consigo o viés conservador como característico dos grandes proprietários da mídia brasileira. Por um lado exaltavam o livre-comércio, por outro eram conservadores no que tange direitos sociais e políticos da sociedade (VIEIRA, 2007). Neste mesmo período emerge uma crescente oposição dos jornais que manifestavam uma ruptura do Brasil com a Corte portuguesa. Assim, ações de censura e perseguição a jornalistas denunciavam os limites da liberdade de expressão. Há exemplo, em 20 de novembro de 1830, o jornalista Líbero Labaró é assassinado por uma publicação no seu jornal o Observador Constitucional que saudava a Revolução Francesa.

Ao longo do século XX outros jornais avançaram pelo Brasil, se remodelando e inovando em conteúdo. Destaca-se a Gazeta de Notícias que circulou entre 1875 e 1942. Este inovou o jornalismo introduzindo romances literários na forma de folhetim inspirado pela novidade oriunda dos jornais franceses. Já no contexto de profundas transformações nos anos de 1920-1930, a imprensa brasileira se moderniza e passa a cobrar mudanças, tanto política quanto tecnológica. Dentre os jornais, 0 Globo, fundado em 1925, atendia aos trabalhadores da classe média e se posicionou a favor da Aliança Liberal e da Revolução de 1930.

Com o avanço do Governo Provisório e o fortalecimento do poder de Vargas, novamente a imprensa tem papel importante como oposição e formadores de opinião. Assim, durante o Estado Novo (1937-1945) a censura imposta por Vargas cercou e limitou a atuação da imprensa brasileira. Assassinatos, prisões arbitrarias de jornalista, destruição de gráficas e desapropriações de jornais foi uma constante nesse período (VIEIRA, 2007).

Já nas décadas de 1950, agências mundialmente conhecidas nos ramos de negócios, incentivavam o avanço do capitalismo industrial, em um contexto aonde até pouco tempo observava resquícios de uma sociedade arcaica e escravista. No entanto, o avanço da industrialização no Brasil após 1950 trouxe consigo uma nova relação entre o empresariado e a imprensa. Esta última começou a lucrar enormemente com grandes anúncios assessorados por agencias publicitarias, que exploravam a onda consumista do momento (VIEIRA, 2007).

O período da ditadura militar (1964-1985) reflete novamente o comportamento contraditório dos grandes jornais que nunca mantiveram a imparcialidade e nem o jogo democrático no país. Pois, em primeiro momento grandes jornais como 0 Globo, 0 Estado de São Paulo, Diário de 
Notícias e a Gazeta Mercantil, apoiaram os militares por se sentirem ameaçadas por um governo com ideias de esquerda. Até mesmo o Jornal da Amanhã, tradicionalmente defensor da democracia e dos valores liberais, fez forte oposição ao governo de João Goulart e defendeu o golpe militar explicitamente em três editoriais lançados durante o golpe em 31 de março (SINGER, 2001).

Neste período, o governo militar reformulou a estética e gráfica da imprensa nacional. Os militares viram na modernização dos meios de comunicação importante ferramenta de integração cultural e econômica do país (RODRIGUES, 2009). Fruto do investimento do Estado foi criado a Empresa Brasileira de Telecomunicação (Embratel) em 1965, e os modernos parques gráficos e integração por satélite das comunicações.

Marcado ainda pela onda de fusões, incorporações e formação de grandes redes de comunicação, a ditadura militar contribuiu enormemente para o monopólio midiático e consequente marginalização da mídia alternativa (RODRIGUES, 2009). No processo de modernização da imprensa, nasce em 1968 a revista Veja se apresentando futuramente como um grande semanário de expressiva circulação e consumo.

Atualmente, sete grupos controlam cerca de $80 \%$ de toda informação propagada pelos diversos modais comunicativos no Brasil (RODRIGUES, 2009, CAPARELLI; LIMA, 2004):

1. A família Marinho detêm a TV aberta (Rede Globo), sendo esta a coluna espinhal das Organizações Globo de Televisão e do jornal impresso: 0 Globo, que atualmente é o jornal entre as três maiores tiragens.

2. A igreja Universal do Reino de Deus é proprietária do segundo maior canal da TV aberta do país, a Rede Record.

3. A família Abravanel são donas da terceira maior emissora de TV, o SBT.

4. O jornal mais lido do país, Folha de São Paulo, pertence à família Frias, que também possuem um instituto de pesquisa de opinião pública, o DataFolha, além do OUL, a Agência Folha e um jornal de economia em parceria com o grupo Globo, o Valor Econômico.

5. A família Saad controla a Rede Bandeirantes, as emissoras da Rádio Bandeirantes AM e FM, e ainda o Canal 21 de grande acesso na capital paulista.

6. O segundo maior jornal do país, o Estado de São Paulo, pertence à família Mesquita, além de emissoras de rádio, e um canal de TV no Estado do Maranhão. 
7. A Abril é outro monopólio midiático, porém apresenta características singulares comparadas as outras, pois tem grandes influências estrangeiras no seu conteúdo, além de receber capital externo. Tem ainda domínios em revistas, musicas e na TV a cabo.

Conforme se observa nos dados acima, a realidade brasileira aponta para uma concentração da mídia estimulada a partir de 1960, e evidenciada em poucos nomes que controlam quase totalmente o que chegam ao conhecimento do público. Tais fatores resultam de conjunturas políticas e empresariais que em uma perspectiva capitalista, moldaram a mídia para uma superestrutura centralizada, o que reproduz os conceitos da globalização, padronizando a informação, o consumo e a ideia de neutralidade (RODRIGUES, 2009).

\subsection{A RELAÇÃO ENTRE A MÍDIA TRADICIONAL E O MST}

Existe no Brasil um passe de mágica intelectual, ou um truque epistemológico que consiste no seguinte: problemas antigos e que continuam sem solução são dados como resolvidos. Ou passam à categoria de problemas chatos, obsoletos. Arrisca-se, por isso, a um certo ridículo quem fala ainda em reforma agrária. No Brasil, o argumento principal ficou sendo o de que a agricultura hoje nada mais é do que a parte antiquada da agroindústria moderna. A indústria domina o campo e as multinacionais, a indústria. Falar em camponês, parceiro, meeiro, peão - prossegue o argumento- Seria falar nos direitos de servo da gleba, escudeiros ou palafreneiros (Callado, 1985).

Quando Antônio Callado em seu livro de 1985 "Entre Deus e a vasilha" diz que como um truque epistemológico problemas antigos sem solução são dados por resolvidos, ele faz uma profunda constatação sobre como a questão da reforma agrária está presente, ou melhor, ausente no cotidiano. Pois, o que predomina até os dias atuais é o silêncio conivente sobre o tema, fazendo do assunto um tabu.

Em sua opinião, falar em reforma agrária no Brasil é se arriscar a ser taxado de comunista, antiquado, ou simplesmente iludido. Mas qual a razão de um assunto que deveria estar nas pautas diárias da imprensa, na boca do trabalhador e nas discussões dos jovens do ensino médio e universitários pelo país? Na visão de Bertol (2003) tal fato ocorre por predominar um discurso formado baseado na defesa da propriedade privada e da permanência do status quo.

Segundo Ayoub (2006) em seu trabalho "Mídia e movimentos sociais: a satanização do MST na Folha de S. Paulo" a imprensa tem um papel enquanto representação de classe. A mídia defende seus interesses e ataca os que contestam a hegemonia burguesa. A questão ideológica fica clara neste processo e permite entender a forte ligação entre classes dominantes e proprietários da grande imprensa no Brasil. Os meios de comunicação são usados no embate, independentemente dos princípios de liberdade e isenção que são defendidos em público. 0 fenômeno se justifica a partir do momento em que ambas se situam no espaço, reproduzindo seus valores. A grande imprensa que por 
não menos se consolida como monopólio, reflete a lógica capitalista na estrutura oligárquica, tornando-se assim instrumento da indústria cultural e reproduzindo sua condição como corporação.

Na visão de Adissi (2010), a grande mídia se apresenta como um quarto poder do Estado que ao longo do tempo tratou por criminalizar os movimentos sociais. 0 conceito de criminalização do MST se insere no próprio antagonismo entre as distintas categorias, configurando na luta de classe. Para Ayoub (2006) a mídia desempenha o papel voltado à disseminação de um consenso previamente acordado entre as elites em espaços reservados, e em menor escala, a difusão de proposições de grupos de pressão empresarial.

Assim, partindo do pressuposto que os meios de comunicação de massa difundem sua hegemonia e que as notícias majoritariamente são divulgadas pelos jornais e TV, fica nítido observar o aparelhamento da opinião pública com o discurso jornalístico. Tem-se o predomínio de uma formação discursiva resultado do discurso midiático hegemônico (BRANDÃO; DIAS, 2007).

Vejamos que dentre as narrativas usadas pela grande imprensa como forma de marginalização, destaca-se pelo menos oito estratégicas narrativas que visam desconstruir a imagem do MST, e/ou construir uma narrativa entre a população da rejeição. Destacamos alguns recortes de revistas online sobre diversas coberturas nas ações do MST, de acordo com os principais canais de comunicação:

Tabela 1: Narrativas utilizadas para a marginalização do MST

\begin{tabular}{|c|c|c|}
\hline Narrativas & Trechos & Fonte \\
\hline $\begin{array}{c}1^{\circ} \text { O Movimento } \\
\text { prega a violência: }\end{array}$ & $\begin{array}{c}\text { "Em uma ação criminosa e obscurantista, } \\
\text { cerca de mil mulheres do Movimento dos Sem- } \\
\text { Terra (MST) depredaram e destruíram nesta } \\
\text { quinta-feira mudas de árvores transgênicas } \\
\text { que eram objeto de pesquisa..." }\end{array}$ & VEJA/Revista virtual. \\
\hline $\begin{array}{c}2^{\circ} \text { O movimento } \\
\text { depreda o } \\
\text { patrimônio } \\
\text { privado: }\end{array}$ & $\begin{array}{c}\text { "Em uma ação criminosa e obscurantista, } \\
\text { cerca de mil mulheres do Movimento dos Sem- } \\
\text { quinta-feira mudas de árvores transgênicas } \\
\text { que eram objeto de pesquisa..." }\end{array}$ & VEJA/Revista virtual \\
\hline $\begin{array}{c}3^{\circ} \text { O movimento } \\
\text { depreda bens } \\
\text { públicos: }\end{array}$ & $\begin{array}{c}\text { "PF investiga depredação e roubo no Incra. } \\
\text { participação de integrantes do MST em atos de } \\
\text { depredação e roubo na superintendência do } \\
\text { Incra em Recife (PE)." }\end{array}$ & \\
\hline
\end{tabular}




\begin{tabular}{|c|c|c|}
\hline $\begin{array}{l}4^{\circ} 0 \text { movimento é } \\
\text { composto por } \\
\text { bandidos: }\end{array}$ & $\begin{array}{c}\text { “Com lenços encobrindo o rosto, barras de } \\
\text { ferro, machados e facões em punho, elas } \\
\text { bloquearam e picharam a entrada da empresa. } \\
\text { " / "PF investiga depredação e roubo no } \\
\text { Incra: Além de alimentos, R } \$ 50 \text { teriam } \\
\text { desaparecido da lanchonete. Também teriam } \\
\text { sumido quatro lixeiras, um microfone e } \\
\text { cortinas." }\end{array}$ & $\begin{array}{l}\text { VEJA/Revista virtual / } \\
\text { www1.folha.uol.com.br }\end{array}$ \\
\hline $\begin{array}{l}5^{\circ} 0 \text { movimento } \\
\text { usa armas em suas } \\
\text { ações: }\end{array}$ & $\begin{array}{c}\text { De acordo com um dos líderes, havia homens } \\
\text { armados durante a madrugada. As armas } \\
\text { foram escondidas quando a polícia chegou, } \\
\text { por volta das } 6 \mathrm{~h} \text {. }\end{array}$ & http://www1.folha.uol.com.br \\
\hline $\begin{array}{l}6^{\circ} \text { Os assentados } \\
\text { vendem suas } \\
\text { terras: }\end{array}$ & $\begin{array}{c}\text { "Assentados do MST vendem terras de } \\
\text { reforma agrária" } \\
\text { "A comercialização e o arrendamento de } \\
\text { terras de assentamentos da reforma agrária } \\
\text { são proibidos por lei. Veja flagrantes de venda } \\
\text { ilegal no Rio Grande do Sul. " }\end{array}$ & http://g1.globo.com \\
\hline $\begin{array}{l}7^{\circ} 0 \text { movimento } \\
\text { prega tácticas } \\
\text { terroristas: }\end{array}$ & $\begin{array}{l}\text { “(...)A ação na Maria Bonita foi comparada à } \\
\text { utilizada pelas Forças Armadas } \\
\text { Revolucionárias da Colômbia (Farcs), de quem } \\
\text { supostamente o MST estaria recebendo } \\
\text { treinamento, segundo informação investigada } \\
\text { pela Secretaria de Segurança Pública do Pará. ” }\end{array}$ & http://diariodopara.com.br \\
\hline $\begin{array}{l}8^{\circ} 0 \text { movimento } \\
\text { por detrás da } \\
\text { bandeira da } \\
\text { reforma agraria, } \\
\text { instaura uma } \\
\text { revolução } \\
\text { socialista: }\end{array}$ & $\begin{array}{c}\text { “(...). Numa palavra, o MST não quer mais } \\
\text { terra. O movimento quer toda a terra, quer } \\
\text { tomar o poder no país por meio da revolução } \\
\text { e, feito isso, implantar por aqui um socialismo } \\
\text { tardio(...)” }\end{array}$ & (http://veja.abril.com.br/idade/educacao) \\
\hline
\end{tabular}

Fonte: Elaborado pelos autores, 2017.

Como observado acima, o breve quadro analítico ilustra algumas das narrativas construídas na qual a mídia brasileira segue uma linha de marginalização amplamente propagada pelos noticiários. 0 foco é mostrar o movimento como uma organização constituída por vândalos e ladrões, que buscam depredar, roubar e expropriar a propriedade privada. Este discurso, moldado por uma visão que seleciona acontecimentos que projetam uma ideia negativa ao movimento, chega ao nível do sensacionalismo quando fazem analogias ou atribuem acontecimentos inexistentes, ou no mínimo sem provas suficientes sobre o MST.

Segundo Gramsci (1980) a classe dominante como dona dos meios de produção e por consequente difusora do material cultural, ao propagar sua concepção do mundo à classe subalterna, a modela ou reforma à opinião civil. Assim, vemos o papel hegemônico perpetrado pela mídia brasileira, que segue como um braço do Estado burguês, atuando como mantedora da ordem vigente, ou na visão de Adissi (2010) que tem como função a marginalização de uma força social que se opõe a concepção do mundo capitalista. 


\section{METODOLOGIA}

Para Minayo (2007) a metodologia constitui o caminho do pensamento percorrido pelo investigador para a obtenção do conhecimento desejado. Como etapas da metodologia no campo das Ciências Sociais, uma possível categorização é a subdivisão em: natureza da pesquisa, estratégia de pesquisa, técnicas de coletas de dados e procedimentos para a interpretação dos dados.

Neste trabalho a natureza da pesquisa se classifica como exploratória. Entende-se por pesquisa exploratória aquela que tem o objetivo de proporcionar a visão geral, de tipo aproximativo, acerca de um determinado fato. Este tipo de pesquisa é realizado especialmente quando o tema escolhido é pouco explorado e tornam-se difícil sobre ele formular compreensões, pressupostos, teorias e ou hipóteses precisas e operacionais (GIL, 2006). No presente trabalho, a relação com a sua natureza se justifica pela ausência de estudos na literatura que estabelecem uma investigação da compreensão dos estudantes de um curso de Agronomia sobre o MST.

Quanto à estratégia de pesquisa, o trabalho se baseou em um estudo de caso. Segundo Roesch (1999), o estudo de caso possibilita um aprofundamento a respeito de um fenômeno de acordo com o contexto no qual ele se insere, podendo analisá-lo sobre vários ângulos. 0 estudo de caso se mostra vantajoso na medida em que é possível tanto fazer uma análise mais ampla, quanto enfatizar determinadas áreas e aspectos situacionais. No artigo, o caso investigado se tratou da percepção de um grupo específico de estudantes e a sua relação com as narrativas da mídia. A justificativa para a escolha deste recorte empírico ocorreu pelo fácil acesso às informações, devido à presença de estudantes envolvidos voluntariamente na pesquisa que estavam alocados no contexto organizacional analisado.

No que se refere à técnica de coleta de dados, foi utilizada a aplicação de questionários estruturados com os discentes do curso de Agronomia de uma universidade pública. Entende-se por questionários estruturados, desenhos de investigação onde se pretende obter informação quantificável de um número elevado de entrevistados, com o objetivo de estabelecer frequências que permitam um tratamento estatístico posterior (GIL, 2006). Deste modo, o questionário de natureza quantitativa buscava compreender o nível de conhecimento relacionado ao MST, bem como as opiniões dos estudantes sobre as causas e ações do Movimento.

O questionário foi aplicado no período de novembro a dezembro de 2016, com um recorte não amostral ${ }^{5}$, contemplando 100 respondentes do curso de Engenharia Agronômica de uma universidade Federal em Minas Gerais ${ }^{6}$. Em termos gerais, o presente campus da universidade conta 850 estudantes, nos quais 300 estão matriculados no curso de Engenharia Agronômica.

\footnotetext{
50 estudo ao partir de um recorte não amostral, não teve a pretensão de entrevistar todos os discentes do curso. 0 esforço, no entanto, não descaracterizou o esforço de aplicar o questionário ao maior número de discentes do curso analisado.

${ }^{6}$ Por questões éticas, optou-se por não explicitar qual a instituição federal analisada.
} 
Durante a aplicação dos questionários, buscou-se contemplar de forma homogênea os estudantes do primeiro ao décimo período do curso, para compreender se ocorriam distinções de opiniões de acordo com o tempo de curso. Para tal, a aplicação dos questionários deu-se por entrevistas aleatórias pelo Campus, sendo aplicados nos corredores dos prédios, pelo pátio do campus, e em alguns casos antes do início das aulas.

A primeira fase do questionário foi constituída de perguntas que objetivavam caracterizar e descrever o perfil dos estudantes respondentes pelo sexo, idade e período que cursavam a Agronomia. A segunda fase do questionário visava compreender quais os canais de comunicação que esses estudantes obtinham como fonte para informações sobre o MST. Por fim, o último grupo de perguntas investigava as opiniões dos discentes sobre o MST e sua relação com as narrativas da grande mídia (Anexo 1).

Quanto à análise dos dados gerados pelo questionário estruturado, foi utilizado o Software estatístico SPSS (Statistical Package for the Social Sciences), licenciado, que possibilitou por meio de ferramentas estatísticas, transformar os dados quantitativos em informações estatísticas descritivas relevantes acerca da compreensão do tema entre os discentes entrevistados. Após a geração estatística, as opiniões dos discentes foram confrontadas com o discurso hegemônico da grande mídia, estabelecendo paralelos e singularidades.

\section{RESULTADOS E DISCUSSÕES}

Os primeiros resultados da pesquisa visavam traçar um perfil dos discentes respondentes do Curso de Agronomia analisado. Deste modo, observou-se que 55\% dos entrevistados eram do sexo feminino e $45 \%$ do sexo masculino (Tabela1). Os dados estão alinhados com o perfil do Campus, onde estudos internos do Controle de Informação Estudantil da Universidade apontam para resultados similares. É relevante considerar que se historicamente os cursos de Ciências Agrárias tinham uma formação majoritariamente masculina, nas últimas décadas esta realidade tem mudado em esfera nacional. Os próprios dados do Censo da Capes apontam para um aumento gradual de $5 \%$ ao ano no número de pesquisadoras no Brasil (CAPES, 2017).

Tabela 1: Distribuição dos estudantes entrevistados em função do gênero

\begin{tabular}{|c|c|c|}
\hline Gênero & Frequência & Percentual (\%) \\
\hline Feminino & 55 & 55 \\
\hline Masculino & 45 & 45 \\
\hline Total & $\mathbf{1 0 0}$ & $\mathbf{1 0 0}$ \\
\hline
\end{tabular}

Fonte: Elaborado pelos autores, 2017. 
Referente à idade dos entrevistados e o período vigente do curso durante a entrevista, registrou-se que a média de idade dos entrevistados era de 22 anos e que a distribuição dos respondentes por período apresentou um caráter homogêneo. Com exceções dos discentes situados nos 5, 8 e 9 períodos, as médias de estudantes entrevistados variaram de 9 a 13 respondentes por turma (Tabela 2).

Tabela 2: Distribuição dos estudantes entrevistados em função de seus períodos acadêmicos

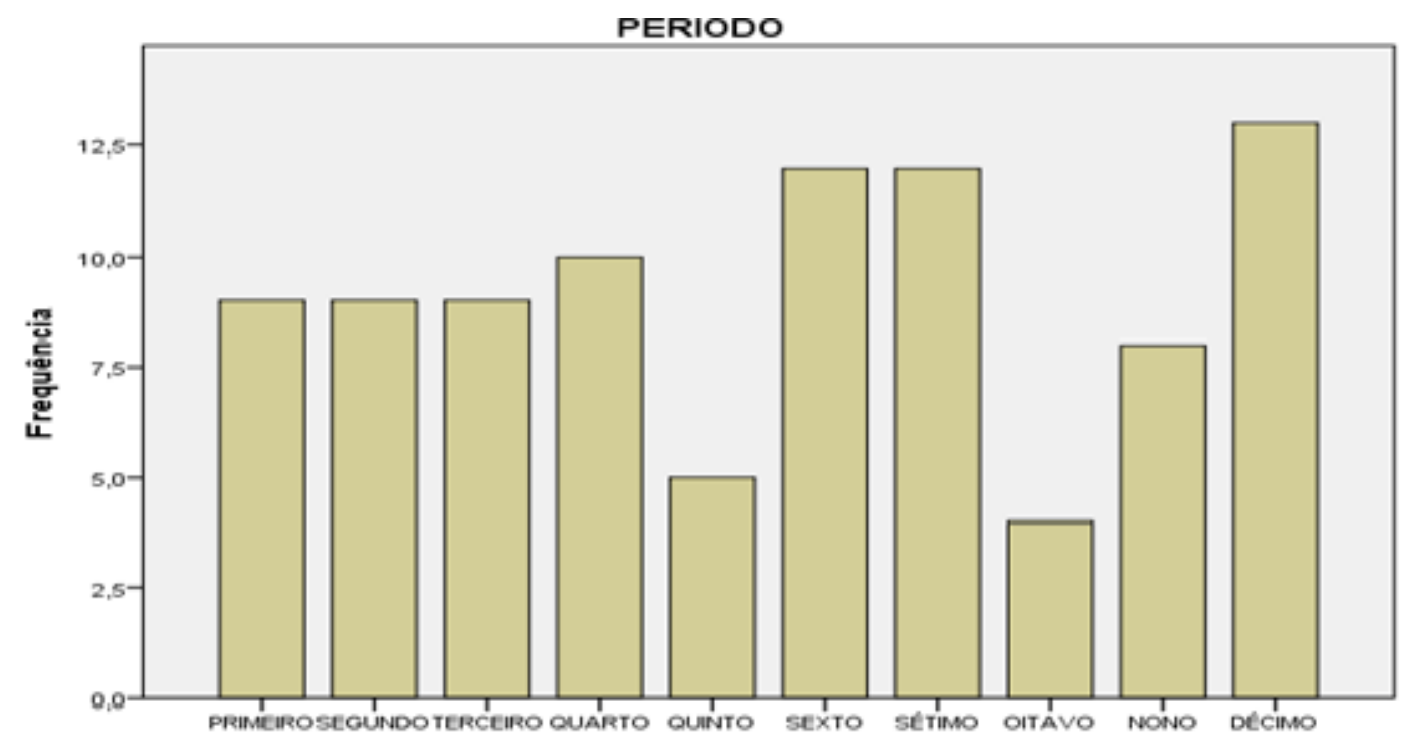

Fonte: Elaborado pelos autores, 2017.

Feitas às caracterizações iniciais do perfil dos entrevistados, o segundo grupo de perguntas buscava compreender por meio de quais canais de informação os discentes obtiveram informações sobre o MST. Para tal, a primeira questão indagava se os mesmos já haviam participado de alguma discussão dentro da universidade. Constatou-se que apenas 14\% dos universitários responderam que haviam participado de alguma discussão. Em contrapartida, 85\% dos respondentes afirmaram que nunca discutiram o tema dentro deste espaço (Tabela 3).

Esses dados chamam atenção, primeiramente porque o contexto universitário não abarca somente as discussões na sala de aula, como também projetos de iniciação científica, atividades extensionistas, ou ainda movimentos estudantis e semanas acadêmicas da área de Agronomia. Da mesma forma, se considerarmos o peso que o MST possui enquanto o maior movimento da América Latina e sua íntima relação com as Ciências Agrárias (o objeto de estudo é a propriedade da terra e sua produção), a não discussão do tema em um espaço aberto para as críticas é preocupante. 
Tabela 3: discussão vinculada ao MST na universidade

\begin{tabular}{|c|c|c|}
\hline $\begin{array}{c}\text { Participação em debates } \\
\text { Sobre o MST }\end{array}$ & Frequência & Percentual (\%) \\
\hline Não & 85 & 85 \\
\hline Sim & 14 & 14 \\
\hline Não respondeu & 1 & 1 \\
\hline Total & $\mathbf{1 0 0}$ & $\mathbf{1 0 0}$ \\
\hline
\end{tabular}

Fonte: Elaborado pelos autores, 2017.

No mesmo sentido, a segunda questão buscou ampliar a compreensão sobre os canais de informação pelos quais os discentes obtiveram informações sobre o MST. Para tal, foi listado um conjunto de meios de informação (TV, Jornais, Revistas, Redes Sociais, Radio, Amigos e Familiares, Sala de Aula, Projetos) ao qual era permitido selecionar mais de uma alternativa. Observou-se com as respostas que para $86 \%$ dos entrevistados o principal canal de informação foi a Televisão. Em seguida, os jornais com $48 \%$, as redes sociais com $41 \%$, as revistas com $24 \%$ e o rádio com $18 \%$. Constatou-se ainda que as salas de aulas, as pesquisas e extensões representaram apenas $12 \%$ e $3 \%$ dos entrevistados, respectivamente, o que corrobora com os dados anteriores referentes à baixa discussão dentro da Universidade (Tabela 4).

Com os dados apresentados, pode-se inferir que se por um lado o espaço universitário analisado não vem construindo ou desconstruindo uma narrativa referente ao MST, por outro, os canais enumerados pelos discentes apontam para formadores de opinião centrados em grupos hegemônicos.

Tabela 4: meios de comunicação você obteve informações sobre o MST

\begin{tabular}{|c|c|c|}
\hline Tipos de mídia & Frequência & Percentual (\%) $^{\mathbf{7}}$ \\
\hline TV & 86 & 86 \\
\hline Jornal & 48 & 48 \\
\hline Redes sociais & 41 & 41 \\
\hline Revistas & 24 & 24 \\
\hline Rádios & 18 & 18 \\
\hline Amigos e / ou familiares & 12 & 12 \\
\hline Salas de aulas & 12 & 12 \\
\hline Pesquisadores/ Extensão & 3 & 3 \\
\hline Outros & 1 & 1 \\
\hline
\end{tabular}

Fonte: Elaborado pelos autores, 2017.

Compreendidos os canais de informação por meio dos quais os discentes entrevistados obtêm informações sobre o MST, no terceiro momento da pesquisa buscou-se estabelecer os paralelos

\footnotetext{
${ }^{7}$ Os números excedem $100 \%$ por ser uma questão que permite que a seleção de mais de um item.
} 
da possível influência da mídia na opinião dos entrevistados. Neste sentido, a primeira questão tratou de compreender na opinião dos estudantes quais as raízes históricas da formação do movimento, questionando-os por que o MST existe?

A pergunta tinha também por objetivo identificar se os mesmos estabeleciam uma relação das condições materiais (desigualdade econômica e social) com a sua formação, ou se a reprodução do discurso hegemônico se manifestava na ideia de que o movimento era baderneiro, os camponeses ignorantes e/ou vinculados aos partidos de esquerda.

Os dados da pesquisa apontaram para uma visão que foge as narrativas da mídia hegemônica apresentada no referencial teórico deste artigo, visto que $60 \%$ dos estudantes atribuíram que a existência do movimento tem seu sentido por não haver terra para todos os camponeses. Ou seja, o movimento surge de uma desigualdade econômica e social. Ainda, 20\% dos respondentes informaram que a existência do movimento é ocorrência do desemprego no país, justificado que em sua ausência os mesmos se articulam para obter terras e direitos dignos de sobrevivência (Tabela 5).

Se por um lado $80 \%$ dos estudantes parecem não reproduzir um discurso midiático hegemônico, por outro 19\% dos respondentes foram fiéis as grandes narrativas de crítica ao Movimento. Observou-se que 8\% responderam que o MST existe porque os camponeses têm ideais comunistas, $5 \%$ porque os camponeses são ignorantes, $4 \%$ porque os camponeses gostam de fazer invasões, e 2\% porque são do Partido dos Trabalhadores (Tabela 5). Estes resultados ilustram as mesmas narrativas construídas pela mídia ao afirmar que o MST é um movimento que por detrás da bandeira da reforma agrária, almeja uma revolução armada socialista (Revista Veja), que o movimento depreda bens privados e públicos (Folha Uol, Revista Veja) e que são um grupo compostos por bandidos (Globo.com, e Folha Uol), conforme visto no referencial teórico.

Tabela 5: Justificativa da existência do Movimento dos Sem-Terra

\begin{tabular}{|c|c|c|}
\hline Causas da existência do movimento & Frequência & Percentual (\%) \\
\hline Porque não há terra para todos os camponeses & 60 & 60 \\
\hline Porque não há empregos para todos os camponeses & 20 & 20 \\
\hline Porque os camponeses têm ideais comunistas & 8 & 8 \\
\hline Porque os camponeses são ignorantes & 5 & 5 \\
\hline Porque os camponeses gostam de fazer invasões & 4 & 4 \\
\hline Porque os camponeses são do PT & 2 & 2 \\
\hline Não respondeu & 1 & 1 \\
\hline Total & $\mathbf{1 0 0}$ & $\mathbf{1 0 0}$ \\
\hline
\end{tabular}

Fonte: Elaborada pelos autores, 2017.

Em consonância com a perspectiva das ações do MST, buscou-se compreender como os estudantes avaliavam as ações do movimento no seu campo de atuação política e de militância. Assim, 
ao questionar: Como você caracteriza as ações do MST? Foi constatado que 32\% acreditam que o MST luta por seus direitos, mantendo uma coerência com as ideias anteriores. Da mesma forma, 41\% defenderam que as suas ações são moderadas, o que também parecem não ilustrar os discursos da grande mídia que enfatiza a violência no movimento (Tabela 6).

Porém, um grupo de estudantes (26\% dos respondentes) semelhantes à resposta anterior, defendeu que o movimento é muito violento (Tabela 6). 0 argumento se assemelha diretamente com as matérias presentes de que o MST prega a violência (Revista Veja), usa armas em suas ações (Folha Uol), bem como, o prega táticas terroristas em suas ações (Diário do Pará).

Tabela 6: caracterização das ações do MST

\begin{tabular}{|c|c|c|}
\hline Caraterização das ações & Frequência & Percentual (\%) \\
\hline Moderado & 41 & 41 \\
\hline Luta por seus direitos & 32 & 32 \\
\hline Muito violento & 26 & 26 \\
\hline Pacifista & 1 & 1 \\
\hline Não respondeu & 1 & 1 \\
\hline Total & $\mathbf{1 0 0}$ & $\mathbf{1 0 0}$ \\
\hline
\end{tabular}

Fonte: Elaborada pelos autores, 2017.

Referente ainda às ações do movimento, se propôs delimitar especificamente as estratégias de ocupações de terras. Para tal, questionou como os estudantes avaliavam as ocupações de terras pelo MST? Observou-se com as respostas que apenas 12\% se manifestaram favorável as ocupações, enquanto que na opinião de $60 \%$ dos estudantes depende de cada ocasião e $28 \%$ se mostraram totalmente contrários às ocupações (Tabela 7).

Esta questão representa o cerne do eixo orientador dos discursos da mídia na crítica às ocupações do MST. Deste modo, ao criminalizar as ações de ocupações de terras do MST, na visão de Bertol (2003) tal fato o ocorre por legitimar um discurso formado sobre a questão baseada na defesa da propriedade privada e da permanência do status quo. Ainda para Ayoub (2006) o processo de "satanização" do MST ocorre por via da grande imprensa, porém muitas vezes de formas sutis. 0 exemplo, quando as manchetes usam o termo "invadir" e não "ocupar", já se tem a distorção da ação, sendo ela reproduzida pelo público consumidor da notícia, como uma ação criminosa frente à propriedade privada.

Especificamente em um curso de Agronomia ao quais os estudantes estão inseridos, cuja tensão pela posse da terra e pelo histórico do latifúndio representa um conflito inerente, parece pouco provável que a maioria dos estudantes não sustente a defesa da propriedade privada. 
Tabela 7: opinião sobre as estratégias de ocupações de terras pelo MST

\begin{tabular}{|c|c|c|}
\hline Justificativa & Frequência & Percentual (\%) \\
\hline Depende de cada ocasião & 60 & 60 \\
\hline Sou contra & 28 & 28 \\
\hline Sou a favor & 12 & 12 \\
\hline Total & $\mathbf{1 0 0}$ & $\mathbf{1 0 0}$ \\
\hline
\end{tabular}

Fonte: Elaborada pelos autores, 2017.

Feitas as considerações sobre a análise das ações do MST, buscou-se traçar um paralelo com os princípios do movimento. Para tal, foi questionado se o MST age coerentemente com os seus princípios ou se é um movimento corrupto?

As respostas indicaram que apenas $13 \%$ dos estudantes avaliam que o movimento age extremamente de acordo com seus princípios. A maioria dos estudantes (64\%) afirmou que o movimento age moderadamente em relação aos seus princípios, o que parece apresentar certa tolerância com algumas ações realizadas pelo MST, porém não a sua totalidade (Tabela 8). Por se tratar de um questionário quantitativo, não foi possível identificar quais seriam as ações toleráveis e as intoleráveis.

Em contraponto, 23\% dos estudantes afirmam que o movimento não é coerente com os seus princípios, pois 21\% acreditam que o MST é corrupto e 2\% extremamente corrupto (Tabela 8). A semelhança destas respostas se alinha com as ideias defendias na grande mídia ao apontarem que o movimento é corrupto por venderem as terras conquistas na reforma agrária (Globo.com) ou ainda ao realizarem roubos em momentos de ocupações (Revista Veja e Folha Online).

Tabela 8: Coerência com os princípios do MST

\begin{tabular}{|c|c|c|}
\hline Caraterização das ações & Frequência & Percentual (\%) \\
\hline Age moderadamente & 64 & 64 \\
\hline É corrupto & 21 & 21 \\
\hline Age extremamente de acordo & 13 & 13 \\
\hline Extremamente corrupto & 2 & 2 \\
\hline Total & $\mathbf{1 0 0}$ & $\mathbf{1 0 0}$ \\
\hline
\end{tabular}

Fonte: Elaborada pelos autores, 2017.

Compreendida as concepções dos princípios e ações do MST na visão dos estudantes, buscouse ainda identificar quais as possíveis alternativas para solucionar as demandas do movimento. Observou-se uma coerência com as respostas anteriores que explicavam a causa do seu surgimento, de modo que $67 \%$ dos estudantes afirmaram realizar a reforma agrária, seguido por $27 \%$ que sustentaram a criação de emprego para os participantes (Tabela 9). 
Diferente das respostas anteriores, na qual 28\% dos estudantes sustentavam um discurso semelhante ao da grande mídia, nesta orientação apenas 5\% dos estudantes trouxeram opiniões que criminalizavam o movimento, destes 3\% dos estudantes sugeriram prender todos os participantes do MST e 2\% que defenderam proibir as divulgações das ideias do movimento (Tabela 9).

Tabela 9: Propostas para que o MST deixe de existir

\begin{tabular}{|c|c|c|}
\hline Propostas & Frequência & Percentual(\%) \\
\hline Realizar a reforma agrária & 67 & 67 \\
\hline Criar emprego para todos os participantes do MST & 27 & 27 \\
\hline Prender todos os participantes do MST & 3 & 3 \\
\hline Proibir as divulgações das ideias do MST & 2 & 2 \\
\hline Não respondeu & 1 & 1 \\
\hline Total & $\mathbf{1 0 0}$ & $\mathbf{1 0 0}$ \\
\hline
\end{tabular}

Fonte: Elaborada pelos autores, 2017.

Por fim, as últimas duas perguntas buscavam compreender diretamente qual o alinhamento dos estudantes com o MST. Assim, foi questionada qual a opinião sobre o MST e se os mesmos, na posição de engenheiros agrônomos prestariam serviços técnicos para o MST?

Observou-se na primeira pergunta que apenas 7\% dos estudantes afirmaram concordar plenamente com o Movimento do Sem Terra. Em sintonia com este grupo, mas não na sua totalidade, $29 \%$ dos estudantes assumiram que concordam com o Movimento e suas ações. Por outro lado, a rejeição ao movimento foi marcada por $29 \%$ dos respondentes, na qual $7 \%$ discordam totalmente e $22 \%$ discordam do movimento. Para além desta polarização, chamou a atenção o restante, onde 35\% dos estudantes ressaltaram não ter opinião formada (Tabela 10).

É interessante observar com essas respostas que mesmo o intenso esforço da mídia hegemônica em criminalizar o MST e compreendendo que a categoria de estudantes obtiveram informações sobre o movimento da grande mídia (conforme Tabela 3), as estratégias não foram por todo efetivas. Da mesma forma, talvez o baixo debate dentro do ambiente universitário sobre o movimento, suas causas e soluções, seja um explicação pelo fato de $35 \%$ dos estudantes ainda não terem nenhuma opinião formada.

Tabela 10: Opinião geral sobre o MST

\begin{tabular}{|c|c|c|}
\hline Concepção sobre o MST & Frequência & Percentual (\%) \\
\hline Não tenho opinião formada & 35 & 35 \\
\hline Concordo & 29 & 29 \\
\hline Discordo & 22 & 22 \\
\hline Discordo totalmente & 7 & 7 \\
\hline Concordo totalmente & 7 & 7 \\
\hline Total & $\mathbf{1 0 0}$ & $\mathbf{1 0 0}$ \\
\hline
\end{tabular}

Fonte: Elaborada pelos autores, 2017. 
No que se refere à possibilidade de prestar algum tipo de serviço técnico ao MST enquanto profissional da área registrou-se que $68 \%$ dos estudantes afirmariam a realização do trabalho, enquanto 32\% negaram esta possibilidade (Tabela 11).

Tabela 11: Prestação de serviços para o MST enquanto Agrônomo

\begin{tabular}{|c|c|c|}
\hline $\begin{array}{c}\text { Prestaria Serviços } \\
\text { ao MST }\end{array}$ & Frequência & Percentual (\%) \\
\hline Sim & 68 & 68 \\
\hline Não & 32 & 32 \\
\hline Total & $\mathbf{1 0 0}$ & $\mathbf{1 0 0}$ \\
\hline
\end{tabular}

Fonte: Elaborada pelos autores, 2017.

A resposta representa uma dimensão crítica interessante, pois se os estudantes estão inseridos em um sistema capitalista cuja lógica é a maximização dos retornos financeiros, um grupo formado por $32 \%$ dos respondentes, que em sua maioria defendem a propriedade privada e a permanência do status quo, afirmaram abrir mão de um trabalho, de uma remuneração, por diferenças ideológicas para não prestar nenhum tipo de serviço técnico ao MST, se um dia fosse convidado (Tabela 11).

Especificamente este grupo de estudantes parece ter incorporado na integra as narrativas da grande mídia. Pois, ainda que a propriedade privada seja um roubo (na visão de Proudhon), somente seria antiético e injustificável o acúmulo do capital, se o trabalho fosse voltado para um grupo de criminosos, de bandidos, como é transmitida a imagem do Movimento nos canais hegemônicos de comunicação.

\section{CONSIDERAÇÕES FINAIS}

O presente trabalho teve por objetivo analisar a influência da mídia sobre a percepção do MST nos estudantes de um curso de engenharia Agronômica. Por meio de uma pesquisa quantitativa onde 100 estudantes responderam ao questionário, foi observado que o debate sobre os movimentos dos assentados tem sido pouco discutido no ambiente universitário dos respondentes. A realidade implicou que a baixa discussão neste contexto restringiu a opinião sobre o movimento em diversas questões do questionário aplicado. Em contraponto, a grande maioria dos estudantes $(85 \%$ dos respondentes) apontou que os principais canais de informação sobre o movimento foram grande mídia hegemônica.

No que se refere à influência da grande mídia na opinião dos estudantes, registrou-se que em partes o discurso jornalístico foi reproduzido fielmente por um grupo de estudantes. Este discurso se materializou na visão de que o MST existe por influências subversivas dos partidos de esquerda, pela 
própria ignorância do campesinato e por serem baderneiros (19\% dos entrevistados). Em similaridade, 23\% acreditam que o movimento é corrupto e também violento, e $5 \%$ que o MST tem que ser reprimido, tirando a liberdade dos integrantes, ou proibindo sua liberdade de expressão.

Apesar da replicabilidade do discurso midiático, verificou-se um número maior de estudantes que parecem não compartilhar do mesmo pensamento. Pois, para $60 \%$ dos discentes a falta de terra é a causa da existência do MST, 67 \% dos estudantes acreditam que o MST resolveria seus problemas se ocorresse uma reforma agrária, e 68\% acreditam que o movimento age moderadamente de acordo com os seus princípios.

Com base nos dados, pode-se inferir que se a mídia é responsável pelo trabalho de base no processo de informação do cidadão comum, no entanto, para este grupo de estudantes não aparentou exercer uma influência hegemônica, o que leva a questionar a efetividade das diversas abordagens que buscam marginalizar o movimento. Da mesma forma, o contexto formativo da universidade analisada cumpriu pouco o seu papel de senso crítico ao debater e apresentar outras narrativas referentes às questões que tangenciam o MST.

Se considerarmos que a Agronomia representa um curso estratégico no desenvolvimento do país que atua em uma área historicamente de grande potencial (a agricultura), é fundamental para a democracia e justiça social no Brasil a problematização dos diversos atores envolvidos, bem como, a respectiva participação dos movimentos sociais, conforme o presente trabalho buscou trazer reflexões para a área.

Por fim, é relevante situar que o desenvolvimento da pesquisa empírica ocorreu após o impeachment da Dilma Rousseff (2016), porém anterior ao avanço de um governo de extrema direita recém-eleito e que têm como discurso a eliminação do MST, bem como a estratégia da criação de Fake News e utilização das mídias sociais para a propagação das narrativas.

Enquanto apontamentos e contribuições para estudos futuros sugere-se que o método empírico utilizado no presente trabalho situe o impacto das Fake News e das redes sociais na visão do movimento, e ainda a possibilidade de investigar a realidade de outras instituições de ensino superior, o que pode possibilitar comparações entre cursos de áreas do saber distintas ou mesmo de naturezas jurídicas singulares.

\section{REFERÊNCIAS}

ADISSI, P. O. A Criminalização do MST: mídia porta voz de quem? Um caso de criminalização a trabalhadores sem-terra na Paraíba. IV Simpósio Lutas Sociais na América Latina. Anais... v. 14. 2010.

AYOUB H. A. Mídia e movimentos sociais: a satanização do MST na Folha de S. Paulo.
(Dissertação) Universidade Estadual de Londrina, Londrina, 2006.

BRANDÃO, N, A; DIAS, E, F. A questão da ideologia em Antonio Gramsci. In: Trabalho \& Educação vol.16, no 2 - jul /b dez - 2007.

CAPES. Mulheres são maioria na Pós-Graduação Brasileira, 2017. Disponível em: 
http://www.capes.gov.br/sala-de-

imprensa/noticias/8315-mulheres-sao-maioria-

na-pos-graduacao-brasileira. Acesso em dez, 2017.

FELICIANO, C. A. Movimento camponês rebelde: a reforma agraria no Brasil. São Paulo: Contexto, 2006.

FERNANDES, Bernardo M. A Formação do MST no Brasil. Petrópolis, RJ: Vozes, 2000.

GRAMSCI, A. Maquiavel, a Política e o Estado Moderno. Rio de Janeiro, Civilização Brasileira, 1980.

GIL, A, C. Como elaborar projetos de pesquisa. São Paulo: Atlas, 2006.

MARTINS, J. S. A sociedade vista do abismo: novos estudos sobre exclusão, pobreza e classes sociais. Petrópolis: Vozes, 2002.

MINAYO, M, C. O desafio do conhecimento: pesquisa qualitativa em saúde. São Paulo: Hucitec, 2007.

Movimento dos Trabalhadores Sem Terra. MST: Lutas e conquistas. São Paulo: Secretaria Nacional do MST, 2010.

OLIVEIRA, A, D. A imagem de João Pedro Stédile, líder do MST, na capa da veja. V Encontro Nacional de Estudos da Imagem. Anais... Londrina, 2013.

OLIVEIRA, C. T. F.; NUNES, M. V.; BRAGA, R. S. A construção da autoimagem do MST na sua mídia e suas relações estratégicas de inserção social global. Revista Fronteiras - estudos midiáticos, v. 13, n.3, pp.185-194, setembro/dezembro, 2011.

ROESCH, S, M, A. Projetos de Estágio e de Pesquisa em Administração: guia para Estágios, Trabalhos de Conclusão, Dissertações e Estudos de Casos.

RODRIGUES, F. A concentração midiática brasileira e a desejada liberdade de expressão. In: ENCONTRO NACIONAL DA REFE ALFREDO DE CARVALHO, 7, 2009, Fortaleza. Anais... 2014.

ROCHA, D. O MST no Oeste de Santa Catarina e sua atuação através da imprensa escrita local (1985 1989). Revista Santa Catarina em História, v.7, n.2, 2013.

SINGER, A. Mídia e democracia. Revista USP, n.48, p. 58-67, dezembro/ fevereiro 2001.

SNCR. Sistema Nacional de Cadastro Rural. 2015. Disponível em: http://www.cadastrorural.gov.br/estatisticas/snc r-sistema-nacional-de-cadastro-rural. Acesso em 20 dez 2017. 